\title{
Burden of Anemia in Chronic Kidney Disease: Beyond Erythropoietin
}

\author{
Ramy M. Hanna · Elani Streja · Kamyar Kalantar-Zadeh
}

Received: June 24, 2020 / Accepted: October 3, 2020 / Published online: October 29, 2020

(C) The Author(s) 2020

\section{ABSTRACT}

Anemia is a frequent comorbidity of chronic kidney disease (CKD) and is associated with a considerable burden because of decreased patient health-related quality of life and increased healthcare resource utilization. Based on observational data, anemia is associated with an increased risk of CKD progression, cardiovascular events, and all-cause mortality. The current standard of care includes oral or intravenous iron supplementation, erythropoiesis-stimulating agents, and red blood cell transfusion. However, each of these therapies has its own set of population-specific patient concerns, including increased risk of cardiovascular disease, thrombosis, and mortality. Patients receiving dialysis or those who have concurrent diabetes or high blood pressure may be at greater risk of developing these

R. M. Hanna

Division of Nephrology, Hypertension and Kidney

Transplantation, Harold Simmons Center for

Kidney Disease Research and Epidemiology,

University of California, Irvine School of Medicine,

Orange, CA, USA

E. Streja $\cdot$ K. Kalantar-Zadeh $(\bowtie)$

Division of Nephrology and Hypertension,

University of California, Irvine School of Medicine,

Orange, CA, USA

e-mail: kkz@uci.edu complications. In particular, treatment with high doses of erythropoiesis-stimulating agents has been associated with increased rates of hospitalization, cardiovascular events, and mortality. Resistance to erythropoiesis-stimulating agents remains a therapeutic challenge in a subset of patients. Hypoxia-inducible factor transcription factors, which regulate several genes involved in erythropoiesis and iron metabolism, can be stabilized by a new class of drugs that act as inhibitors of hypoxia-inducible factor prolyl-hydroxylase enzymes to promote erythropoiesis and elevate hemoglobin levels. Here, we review the burden of anemia of chronic kidney disease, the shortcomings of current standard of care, and the potential practical advantages of hypoxia-inducible factor prolyl-hydroxylase inhibitors in the treatment of patients with anemia of CKD.

Keywords: Anemia; Burden; Chronic kidney disease; Erythropoietin; Hypoxia-inducible factor; Iron; Nephrology 
Key Summary Points

Anemia is common in patients with chronic kidney disease and has been associated with increased risk of cardiovascular morbidity and mortality in observational studies as well as decreased patient quality of life and increased healthcare utilization.

The current standard of care includes supplemental iron, erythropoiesisstimulating agents, and red blood cell transfusions, although each has drawbacks.

High doses of erythropoiesis-stimulating agents have been associated with increased cardiovascular complications and mortality.

Hypoxia-inducible factor-prolyl hydroxylase inhibitors are novel treatments for anemia of chronic kidney disease that prevent degradation of the transcription factor hypoxia-inducible factor, which stimulates erythropoiesis to physiologic levels.

\section{DIGITAL FEATURES}

This article is published with digital features, including a summary slide, to facilitate understanding of the article. To view digital features for this article go to https://doi.org/10.6084/ m9.figshare.13035146.

\section{INTRODUCTION}

Anemia is a common complication of chronic kidney disease (CKD), representing a significant burden to patients and healthcare systems $[1,2]$. According to the Kidney Disease: Improving Global Outcomes (KDIGO) clinical practice guidelines, anemia of $\mathrm{CKD}$ is defined as hemoglobin $\quad(\mathrm{Hb})<13.0 \mathrm{~g} / \mathrm{dl}$ for men and $<12.0 \mathrm{~g} / \mathrm{dl}$ for nonpregnant women [3] and largely results from decreased erythropoietin (EPO) production by the failing kidney and/or altered iron homeostasis $[4,5]$. The current standard of care for anemia of CKD includes oral or intravenous (IV) iron, erythropoiesis-stimulating agents (ESAs), and red blood cell (RBC) transfusion, each of which has potential problems and variable effectiveness $[2,3]$. The impact of anemia correction on patient health-related quality of life (HR-QOL) is unknown, and persistent safety issues contribute to uncertainty regarding the optimal target $\mathrm{Hb}$. This article reviews the burden of anemia of CKD, including its impact on mortality and cardiovascular risk, HR-QOL, hospitalization and transfusion needs, iron supplementation needs, the conservative management of CKD to delay dialysis, end-stage renal disease (ESRD) transition outcomes, anemia management at home, and anemia management in transplant recipients. An assessment of the risk to the benefit profile associated with current standard of care and discussion surrounding novel agents in development based on alternative erythropoietic mechanisms are also provided. This article is based on previously conducted studies and does not contain any studies with human participants or animals performed by any of the authors.

\section{DISEASE BURDEN}

\section{Prevalence}

The estimated global prevalence of CKD is $11 \%$ for patients with CKD stage 3 [estimated glomerular filtration rate (eGFR) $<60 \mathrm{ml} / \mathrm{min} /$ $1.73 \mathrm{~m}^{2}$ ] to stage $5\left(\mathrm{eGFR}<15 \mathrm{ml} / \mathrm{min} / 1.73 \mathrm{~m}^{2}\right.$ ) and $13 \%$ for patients with CKD stage 1 (albumin-to-creatine ratio $>30$ plus eGFR $>90 \mathrm{ml} /$ $\mathrm{min} / 1.73 \mathrm{~m}^{2}$ ) to stage 5 [6]. In the US, the prevalence of stage 1-5 CKD was $14.0 \%$ (representing $\sim 31.4$ million people) according to the 2007-2010 data from the National Health and Nutrition Examination Survey (NHANES) [7]. Similarly, the US Centers for Disease Control and Prevention estimated that the prevalence of 
CKD stage 1 to stage 4 (eGFR $15-29 \mathrm{ml} / \mathrm{min} /$ $\left.1.73 \mathrm{~m}^{2}\right)$ was $15 \%(\sim 37$ million people $)$ in 2013-2016 [8].

Anemia prevalence increases with CKD stage. In the NHANES analysis, $15.4 \%(\sim 4.8$ million people) had anemia of CKD, and anemia prevalence was $17.4 \%, 50.3 \%$, and $53.4 \%$ in stages 3,4 , and 5 CKD, respectively [7]. Anemia of CKD prevalence also increases in patients with comorbidities and with age, from $28.0 \%$ in those aged $18-63$ years to $50.1 \%$ in those aged $\geq 66$ years among US patients with nondialysis-dependent (NDD) CKD [1].

\section{Cardiovascular Risk and Mortality}

Anemia, fluid overload, and arteriovenous fistulas can lead to volume overload that ultimately results in cardiomyopathy, including increased left ventricular hypertrophy (LVH), and systolic and diastolic dysfunction [9, 10]. This cardiomyopathy may present as ischemic heart disease or heart failure, even when arterial vascular disease is absent [10]. Anemia has been associated with an increased risk of cardiovascular events and all-cause mortality in a number of observational studies [11-18], and the American Heart Association considers anemia to be a nontraditional (non-Framingham) cardiovascular risk factor in patients with CKD [10]. In a US study of $>900,000$ patients with NDD-CKD, functional iron deficiency anemia was associated with an increased risk of mortality [hazard ratio (HR) 1.11, 95\% CI 1.07-1.14] and an increased relative risk (RR) of cardiovascular hospitalization after 1 year (RR 1.21, 95\% CI 1.12-1.30) and 2 years (RR 1.13, 95\% CI 1.07-1.21) [11]. Similarly, a Danish study of patients with dialysis-dependent-CKD (DDCKD) and NDD-CKD found that anemia was associated with increased risks of major adverse cardiovascular events (MACE), acute hospitalization, and all-cause death [12], and a Japanese study of NDD-CKD patients reported that isolated anemia and iron deficiency anemia were associated with increased risks of cardiovascular-related and all-cause mortality [13]. After adjusting for other cardiovascular risk factors (including age, diabetes, hypertension, and dyslipidemia), patients with anemia in the US Atherosclerosis Risk in Communities (ARIC) study had a significantly increased risk of stroke with comorbid CKD versus no CKD (HR 5.43, 95\% CI 2.04-14.41), whereas in patients without anemia, the risk of stroke with CKD was not significantly increased (HR 1.41, 95\% CI 0.93-2.14) [14]. In patients with diabetes, a pooled analysis of data from the ARIC, Cardiovascular Health, Framingham Heart, and Framingham Offspring studies found an association between anemia and increased risks of the individual and composite outcomes of myocardial infarction (MI), fatal coronary heart disease, stroke, or death, and allcause mortality among patients with comorbid CKD, but not in those without CKD [15]. An association between low $\mathrm{Hb}$ levels and increased risks of cardiovascular and all-cause mortality was also observed in a Korean study of $\sim 300,000$ patients without cardiovascular disease [16]. Furthermore, anemia was associated with increased cardiovascular risk among Japanese patients undergoing treatment for hypertension [17] and in an Italian study of patients with diabetes [18].

However, the association between anemia and cardiovascular morbidity and mortality in patients with CKD is primarily based on observational studies, and randomized interventional trials have yet to demonstrate a reduction in mortality risk with correction of anemia [19]. Notably, clinical trials that attempted to raise $\mathrm{Hb}$ to high levels $(13-13.5 \mathrm{~g} / \mathrm{dl})$ with darbepoetin alfa therapy found an increased risk of mortality or cardiovascular- or renal-related complications compared with a near-normal or low $\mathrm{Hb}$ target $(11.3 \mathrm{~g} / \mathrm{dl}$; HR $1.34,95 \%$ CI 1.03-1.74, $P=0.03$ ) [20] and also an increased risk of fatal or non-fatal stroke compared with placebo (HR 1.92, 95\% CI 1.38-2.68, $P<0.001$ ) [21].

\section{Health-Related Quality of Life}

Anemia of CKD represents an independent risk factor for poor HR-QOL [22]. In patients with CKD anemia, cardiovascular complications are associated with significantly impaired HR-QOL (EQ-5D visual analog scale coefficient -5.68 , $P=0.028$ ) and work productivity (Work 
Productivity and Activity Impairment questionnaire: activity impairment coefficient 8.04, $P=0.032$ ) compared with non-anemic CKD patients [23]. The Centers for Medicare and Medicaid Services states that all dialysis units should actively monitor patient HR-QOL, underscoring the need to understand long-term HR-QOL implications when treating anemia and other comorbidities in patients with CKD [24].

\section{Healthcare Resource Use}

The high prevalence of anemia of CKD represents an important clinical and economic healthcare burden [25]. Patients with moderate $\mathrm{CKD}$ and severe anemia $(\mathrm{Hb} \leq 9 \mathrm{~g} / \mathrm{dl})$ generally require increased hospitalization compared with those without severe anemia [26]. Because patients with CKD and anemia use more overall healthcare resources, their care incurs more costs than those without anemia [1]. In the US, patients with anemia of CKD have estimated total healthcare costs of US\$3800-US\$4800/patient-month [27]; yearly treatment costs among US patients with CKD are estimated to be more than three-fold higher in patients with anemia than in those without anemia [28].

\section{CURRENT STANDARD OF CARE}

Current treatment options for anemia include oral or IV iron, ESAs, and RBC transfusion (Table 1). Although raising Hb levels can lead to improved HR-QOL, morbidity, mortality, and reduced hospitalization [29, 30], increasing $\mathrm{Hb}$ to "normal" levels has led to adverse outcomes highlighting the issues associated with the current standard of care for anemia of CKD.

\section{Iron}

Iron deficiency frequently presents in patients with CKD and is mediated by hepcidin, a hepatic peptide that inhibits iron absorption and release from iron stores and macrophages [5]. Iron deficiency is compounded by increased iron demands with ESAs, which can limit their effectiveness [39]. Supplementary iron can improve physical, cognitive, and immune function [40]. Although less expensive and safer than IV iron, oral iron is poorly absorbed and associated with gastrointestinal adverse reactions [3]. IV iron allows for administration of larger doses with better tolerability and is considered to be superior to oral iron in patients with CKD [41].

Although rare, IV iron administration may be associated with an increased risk of iron overload, which could potentially lead to organ dysfunction in patients with or without ESRD, although end-organ damage due to IV iron has not been demonstrated in clinical studies [42]. Iron overload can also increase infection risk and worsen CKD-associated inflammation, while inflammation can exacerbate oxidative stress caused by IV iron [42, 43]. Previous reports of hypersensitivity with IV iron were largely during the use of high-molecular-weight iron dextrans that are no longer commercially available [44, 45]. IV iron is burdensome in patients with NDD-CKD because of the need for IV access and a transfusion clinic [46].

\section{Erythropoiesis-Stimulating Agents}

ESAs trigger EPO production to increase $\mathrm{Hb}$ and improve anemia [3]. Although ESAs reduce the adverse impact of anemia on morbidity and HRQOL [47], safety concerns regarding the potential increased risk of cardiovascular events with increased ESA doses (due to poor response or a higher $\mathrm{Hb}$ target) have led to reductions in the prescribed ESA dose, increased use of RBC transfusion/IV iron, and uncertainty regarding optimal target $\mathrm{Hb}$ [4]. Consequently, regulatory authorities increasingly require detailed safety data for ESAs. Other considerations for ESA use include parenteral administration, cold storage, expense, and the generation of neutralizing anti-EPO antibodies, which may cause pure red cell aplasia [4]. 
Table 1 Pros and cons of pharmacologic treatment for anemia of chronic kidney disease

\begin{tabular}{|c|c|c|c|}
\hline & Short-acting ESAs & Long-acting ESAs & HIF-PH inhibitors \\
\hline \multirow[t]{7}{*}{ Pros } & $\begin{array}{l}\text { Reduces need for RBC transfusions } \\
\text { [31] }\end{array}$ & $\begin{array}{l}\text { Reduces need for RBC transfusions } \\
\text { [21] }\end{array}$ & \multirow{2}{*}{$\begin{array}{l}\text { Have been shown to be } \\
\text { noninferior to ESAs in raising } \\
\text { or maintaining } \mathrm{Hb}[35]\end{array}$} \\
\hline & May reduce fatigue and improve & May reduce fatigue and improve & \\
\hline & HR-QOL [29] & HR-QOL [29] & Can be administered orally [36] \\
\hline & \multirow[t]{4}{*}{$\begin{array}{l}\text { IV administration is preferred in } \\
\text { patients on hemodialysis [32] }\end{array}$} & $\begin{array}{l}\text { Can be administered less frequently } \\
\text { than short-acting ESAs }[33]\end{array}$ & \multirow{4}{*}{$\begin{array}{l}\text { May reduce the need for iron } \\
\text { supplementation by mobilizing } \\
\text { stored iron [37] }\end{array}$} \\
\hline & & May be cheaper than short-acting & \\
\hline & & ESAs [34] & \\
\hline & & $\begin{array}{l}\text { IV administration is preferred in } \\
\text { patients on hemodialysis [32] }\end{array}$ & \\
\hline \multirow[t]{5}{*}{ Cons } & Higher doses required to reach high & Higher doses required to reach high & \multirow{5}{*}{$\begin{array}{l}\text { Additional research needed to } \\
\text { evaluate potential effects on } \\
\text { tumor growth [36] }\end{array}$} \\
\hline & $\mathrm{Hb}$ targets may increase risk of & $\mathrm{Hb}$ targets may increase risk of & \\
\hline & $\begin{array}{l}\text { adverse cardiovascular outcomes } \\
\text { [20] }\end{array}$ & $\begin{array}{l}\text { adverse cardiovascular outcomes } \\
\text { [21] }\end{array}$ & \\
\hline & $\begin{array}{l}\text { Often requires supplemental iron } \\
\text { administration }[3]\end{array}$ & $\begin{array}{l}\text { Often requires supplemental iron } \\
\text { administration }[3]\end{array}$ & \\
\hline & Administered 3 times per week [31] & $\begin{array}{l}\text { May confer increased risk of mortality } \\
\text { compared with short-acting ESAs } \\
{[38]}\end{array}$ & \\
\hline
\end{tabular}

ESA erythropoiesis-stimulating agent, $H b$ hemoglobin, $H I F-P H$ hypoxia-inducible factor prolyl-hydroxylase, $H R-Q O L$ health-related quality of life, $I V$ intravenous, $R B C$ red blood cell

\section{Impact of ESA-Mediated Anemia Correction}

Hemoglobin normalization in patients with CKD is currently not recommended because of safety concerns related to ESA dosage [48]. Some studies show cardiovascular benefits in treating to a lower $\mathrm{Hb}$ target while others describe poor cardiovascular outcomes with a physiologically normal or supraphysiologic $\mathrm{Hb}$ target, rendering the optimal target $\mathrm{Hb}$ uncertain $[3,4,30]$. Higher ESA dose (rather than higher $\mathrm{Hb}$ ) may cause adverse effects, as ESRD patients who maintain high $\mathrm{Hb}(>12 \mathrm{~g} / \mathrm{dl})$ without ESA therapy do not show increased mortality compared with other patients on dialysis [49]. Current guidelines recommend a target $\mathrm{Hb} \leq 11.5 \mathrm{~g} / \mathrm{dl}$ [3].
Anemia correction with ESAs may provide improvement in cardiovascular parameters, including ejection fraction, left ventricular (LV) mass index, and LV wall thickness [22, 50]. In patients with NDD-CKD, the risk of renal events (i.e., progression to renal replacement therapy, doubling of serum creatinine, or decline in eGFR to $<6 \mathrm{ml} / \mathrm{min} / 1.73 \mathrm{~m}^{2}$ ) was significantly lower in those with $\mathrm{Hb}$ target of $\geq 11 \mathrm{~g} / \mathrm{dl}$ versus $<11 \mathrm{~g} / \mathrm{dl}$ [51]. However, the ACORD, CHOIR, and CREATE studies in patients with NDD-CKD showed no advantage with a high $(13.0-15.0 \mathrm{~g} / \mathrm{dl})$ versus low $(10.5-11.5 \mathrm{~g} / \mathrm{dl}) \mathrm{Hb}$ target in the risk for LVH [52] or cardiovascular events (including sudden death, stroke, transient ischemic attack, MI, acute heart failure, hospitalization for angina pectoris, cardiac arrhythmia, or congestive heart failure, or complication of peripheral vascular disease) 
$[20,53]$. Additionally, in a subanalysis of the TREAT trial, poor initial response to ESA therapy (and consequently higher doses of ESA) in patients with NDD-CKD and type 2 diabetes was associated with increased risks of all-cause death (HR 1.41, 95\% CI 1.12-1.78) and adverse cardiovascular events (HR 1.31, 95\% CI 1.09-1.59) compared with patients with better response to ESA [54]. Due to greater risks for death, MACE, and stroke with target $\mathrm{Hb} \geq 13 \mathrm{~g} / \mathrm{dl}[20,21]$, the US Food and Drug Administration (FDA) recommends that ESA dosing be individualized to the lowest dose necessary to reduce RBC transfusion requirements rather than to a specific target $\mathrm{Hb}$ [48]. Notably, following the FDA communication, there was a $59 \%-74 \%$ decrease in the prescribing of ESAs despite stable anemia prevalence rates [55]. However, there was no corresponding reduction in the rate of mortality or MACE [56].

\section{Impact of ESAs on HR-QOL}

Although benefits are reported often, significant improvements in HR-QOL following ESA treatment of anemia in patients with CKD are inconsistent. ESA therapy was associated with significant improvements in fatigue, vitality, mental health/emotional well-being, and overall physical health in patients with NDD-CKD [20]. Correction of anemia to a target $\mathrm{Hb}$ of 13-15 g/dl improved HR-QOL in patients with CKD with or without diabetes [52, 53] with improvements in several subscales of the Short Form 36 health survey versus a target $\mathrm{Hb}$ of $10.5-11.5 \mathrm{~g} / \mathrm{dl}$ [53]. In contrast, a meta-analysis showed that ESA therapy to obtain higher $\mathrm{Hb}$ targets (10.2-13.6 g/dl) does not improve HRQOL [57]. In patients with CKD on dialysis, ESA therapy is associated with better overall HRQOL and lower costs and healthcare resource utilization compared with no ESA therapy, although there appears to be minimal benefit with higher $\mathrm{Hb}$ targets [58]. Partial correction of anemia with ESAs in dialysis patients has been shown to reduce fatigue and improve exercise tolerance and general well-being, while highdose ESA was associated with increased cardiovascular risk that negatively impacted HR-QOL, thereby resulting in only a modest overall improvement $[59,60]$.

\section{Red Blood Cell Transfusion}

Before ESA availability, frequent RBC transfusion was the primary means of correcting CKD anemia [47]. Currently, $\sim 20 \%$ of patients with NDD-CKD receive RBC transfusions [61]; however, blood volume overload, hyperkalemia, iron overload, blood-borne infections, fever, or allosensitization may occur [3]. Given the burdens associated with RBC transfusion, clinicians should consider alternative treatments for anemia in CKD [61]. However, RBC transfusion may be the only available option in some patients in whom ESAs are not recommended, for example, cancer patients with nonchemotherapy-associated anemia (except for selected patients with myelodysplastic syndrome) [62].

\section{SPECIAL POPULATIONS}

\section{Elderly Patients}

The prevalence of cardiovascular conditions increases in elderly patients with anemia of CKD [1]. Indeed, CKD, anemia, and mobility limitation are important prognostic indicators of mortality risk in elderly patients [63]. Older patients with CKD have higher rates of inflammatory conditions, nutritional deficiencies, and cardiovascular comorbidities, as well as increased hepcidin levels [64], potentially complicating iron and/or ESA therapy. In addition, $\mathrm{Hb}$ decreases with age because of reduced erythropoiesis, so the optimal target $\mathrm{Hb}$ in elderly patients may be lower [64].

\section{Diabetes}

Type 2 diabetes frequently contributes to CKD development and may also increase the risk of anemia in CKD [65]. Diabetes is an inflammatory condition exacerbated by hyperglycemia and other inflammatory disorders, including obesity, arterial hypertension, and 
dyslipidemia; this increased inflammation is thought to cause EPO deficiency in patients with diabetes [66-68]. Deficiencies in EPO and iron, as well as hyporesponsiveness to EPO, are the main mechanisms for anemia development in patients with diabetic kidney disease [69]. In patients with diabetes, anemia is generally more severe, occurs at an earlier stage of CKD, and is associated with a potentially greater risk of cardiovascular disease [70]. Additionally, diabetic macrovascular complications also contribute to the development of atherosclerosis [71], which can further complicate anemia management. However, despite the increased risk of adverse clinical outcomes in patients with diabetes and anemia, there is often clinical inertia regarding initiating IV iron or ESA therapy in these patients [72]. In patients with comorbid diabetes, treatment with the ESA darbepoetin alfa showed no reduction in the risk of composite outcomes (death or cardiovascular event and death or renal event) and an increased risk of stroke versus placebo [21]. In this study, patients with poor initial response to ESA therapy (who received higher ESA doses to meet $\mathrm{Hb}$ targets) had increased risks of all-cause mortality (HR 1.41, 95\% CI 1.12-1.78) and cardiovascular events (HR 1.31, 95\% CI 1.09-1.59) than those with better initial response [54]. This indicates that some patients with diabetes and anemia may benefit from alternative therapies, eliminating the need for ESA dose escalation in those with poor initial response to ESA therapy.

\section{End-Stage Renal Disease}

In patients with stage $3 \mathrm{CKD}$, those who develop anemia have more rapid progression to stage 4 and 5 CKD [73]. Dialysis plays a key role in ESRD management, but HR-QOL for patients with DD-CKD remains a concern, suggesting the need for a more patient-centric assessment [74]. In addition to blood loss associated with hemodialysis, complications of severe anemia contribute significantly to a decreased HR-QOL and increased dependence on RBC transfusion [75]. Iron overload is another concern and was observed in $84 \%$ of patients with DD-CKD treated with ESAs and IV iron [76]. Similar to patients with NDD-CKD, adverse outcomes occur in patients with DD-CKD, with higher mortality rates and no difference in cardiovascular events when epoetin was used to target higher versus lower hematocrit [77]. Notably, attenuation of CKD progression has not been shown with ESA therapy.

\section{Kidney Transplantation}

Anemia prevalence decreases following kidney transplant, from $71 \%$ pre-transplant to $51 \%$ at 6 months and $37 \%$ at 2 years post-transplant. However, post-transplant anemia does occur [78]. In kidney transplant recipients, lower $\mathrm{Hb}$ is a predictor for a return to dialysis, graft failure, subsequent kidney transplant, reduced LV mass index, or death [78, 79]. ESA use to target high $\mathrm{Hb}(12.5-13.5 \mathrm{~g} / \mathrm{dl})$ appears to attenuate the decline of kidney function compared with low $\mathrm{Hb}(10.5-11.5 \mathrm{~g} / \mathrm{dl})$ after 3 years of follow-up in kidney transplant recipients [80]. Of note, patients with ESA hyporesponsiveness before kidney transplant remained hyporesponsive following transplant [81], indicating a need for new therapies to treat anemia in this subpopulation.

\section{EMERGING ALTERNATIVES}

Given the inherent limitations of the current standard of care, new effective and tolerable treatment options for CKD anemia are needed. One particularly promising class of agents in development is hypoxia-inducible factor-prolyl hydroxylase (HIF-PH) inhibitors.

\section{HIF-PH Inhibitors}

Hypoxia-inducible factor (HIF) regulates gene expression in response to hypoxia, including genes involved in erythropoiesis and iron metabolism, promoting iron absorption, iron transport, and heme synthesis (Fig. 1) [37]. Notably, work on the discovery of HIF and its mechanism of action received the 2019 Nobel Prize in Physiology or Medicine. Under 


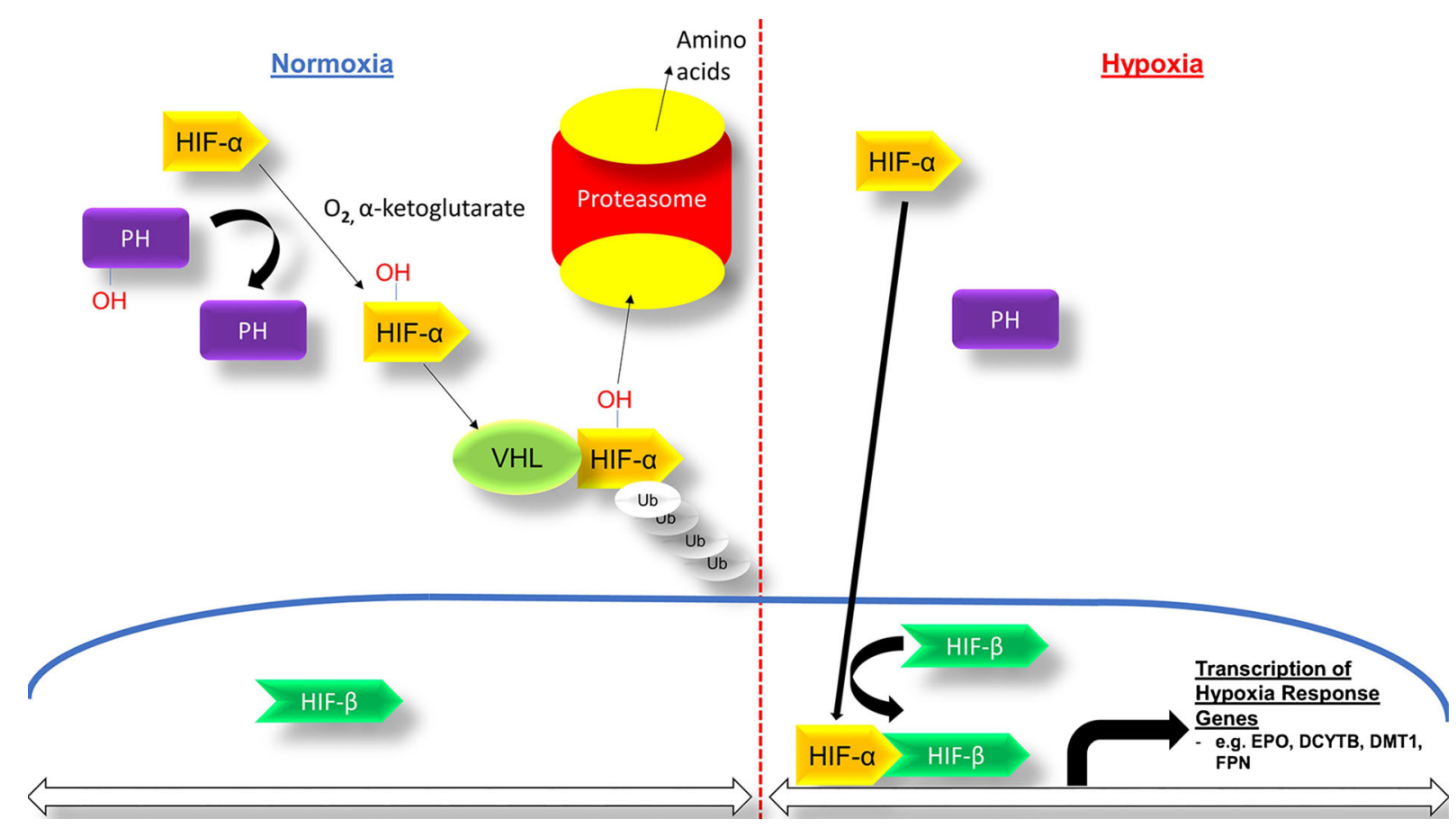

Fig. 1 Hypoxia-inducible factor (HIF) pathway biology. Under normoxic conditions, the HIF- $\alpha$ transcription factor subunit undergoes ubiquitination and proteasome degradation after prolyl hydroxylation (left side of figure). Under hypoxic conditions or pharmacologic HIF prolylhydroxylase inhibition, HIF- $\alpha$ is stabilized and, after heterodimerization with HIF- $\beta$, increases transcription of

normoxic conditions, HIF-PH enzymes promote HIF degradation; thus, selective HIF stabilization with HIF-PH inhibitors is an innovative approach for treating anemia of CKD [36, 82]. Several HIF-PH inhibitors are currently under development (Table 2). HIF-PH inhibitors are orally administered, and significantly lower EPO levels are induced compared with the supraphysiologic levels typically attained with ESA therapy (Fig. 2) [82]. Animal studies have shown that HIF-PH inhibitors stimulate EPO expression in the kidneys and liver, increasing $\mathrm{Hb}$ levels in models of anemia of CKD, including 5/6th nephrectomized rats [83, 84]. HIF-PH inhibitors have also been shown to decrease hepcidin, which may allow patients to mobilize iron stores and lessen iron supplementation needs. Additionally, HIF stabilization should increase gastrointestinal iron absorption through increased expression of divalent metal transporter-1 and duodenal cytochrome B [85]. hypoxia-responsive genes, including those encoding erythropoietin (EPO) and iron metabolism (right side of figure). $D C Y T B$ duodenal cytochrome $\mathrm{B}, D M T 1$ divalent metal transporter 1, EPO erythropoietin, FPN ferroportin, $O H$ hydroxide, $P H$ prolyl hydroxylase, $U b$ ubiquitin, $V H L$ von Hippel-Lindau protein

\section{Approved HIF-PH Inhibitors}

Roxadustat (FG-4592) was the first-in-class HIF$\mathrm{PH}$ inhibitor approved in Japan for the treatment of anemia in patients with DD-CKD [121] and in China for patients with DD-CKD or NDD-CKD [122]. Daprodustat (GSK1278863) and vadadustat (AKB-6548) are also now approved in Japan for the treatment of anemia in patients with DD-CKD or NDD-CKD $[123,124]$. All three HIF-PH inhibitors effectively stimulate EPO production in patients with anemia of $\mathrm{CKD}$, providing dose-dependent increases in $\mathrm{Hb}$ and reductions in hepcidin levels, and thus improving total iron binding capacity (TIBC) $[35,90-93,96-98,103$, 125-127].

In NDD-CKD patients, roxadustat was associated with superior and/or statistically significant $\mathrm{Hb}$ response rates and changes from baseline compared with placebo in a Chinese 


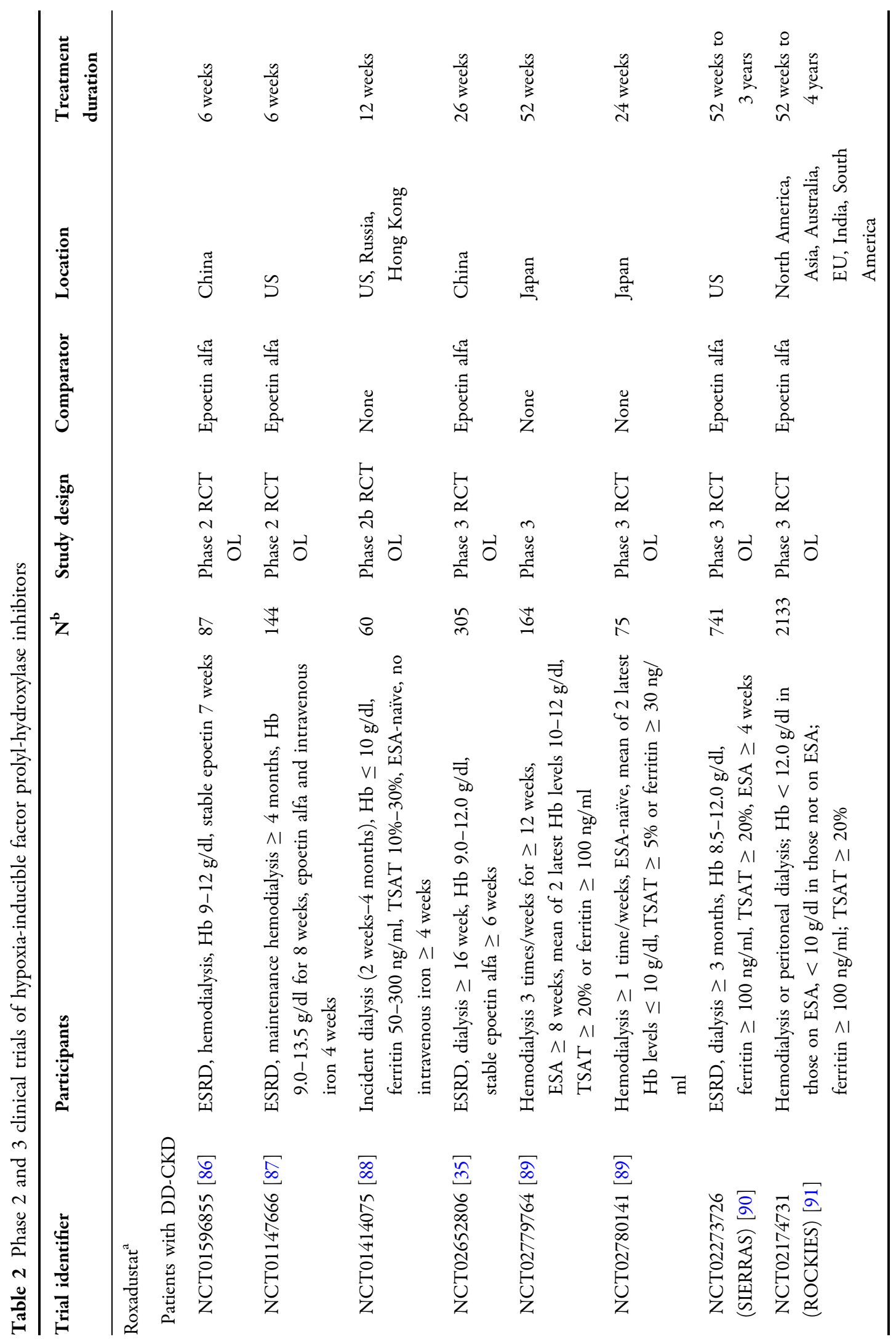




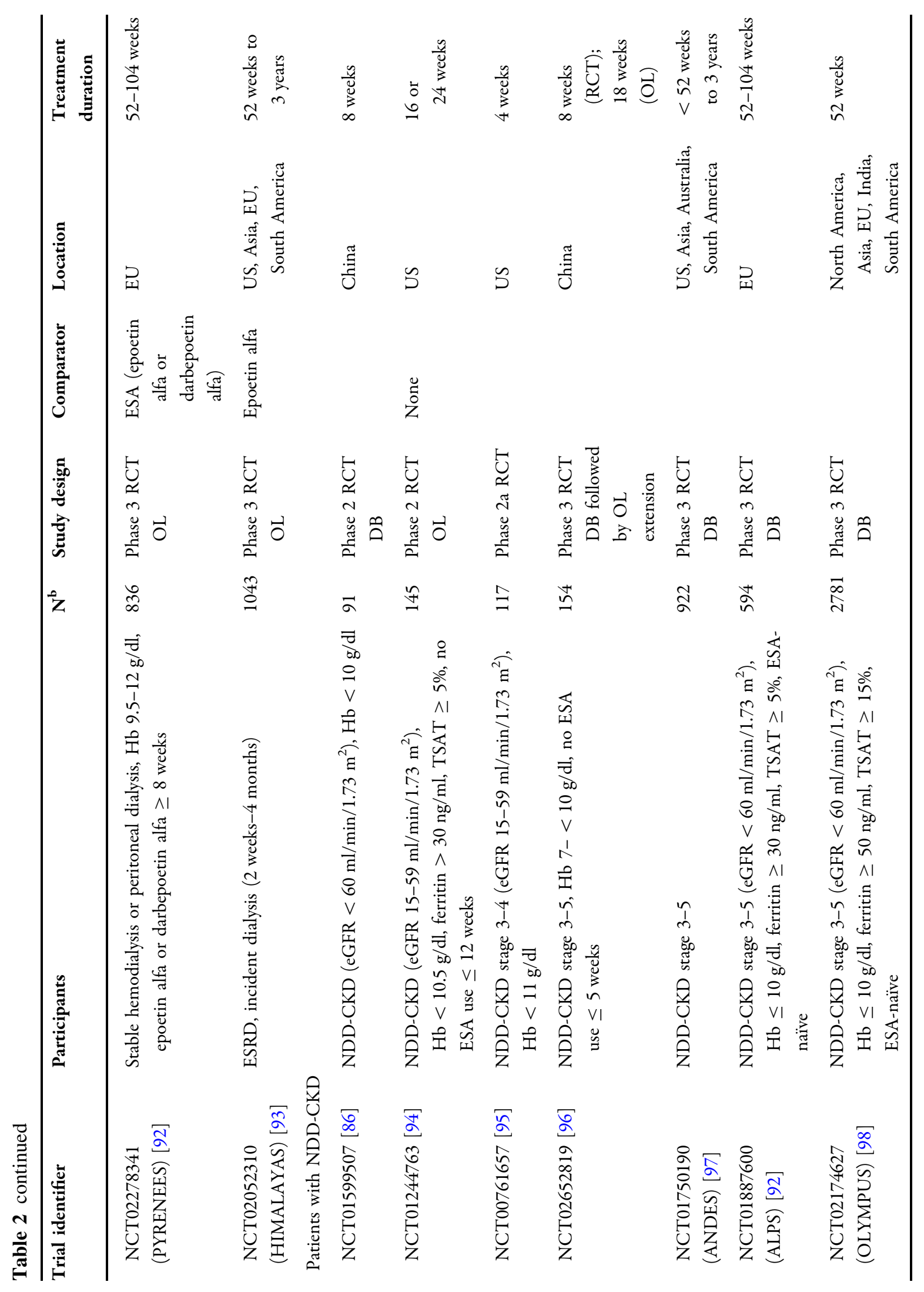









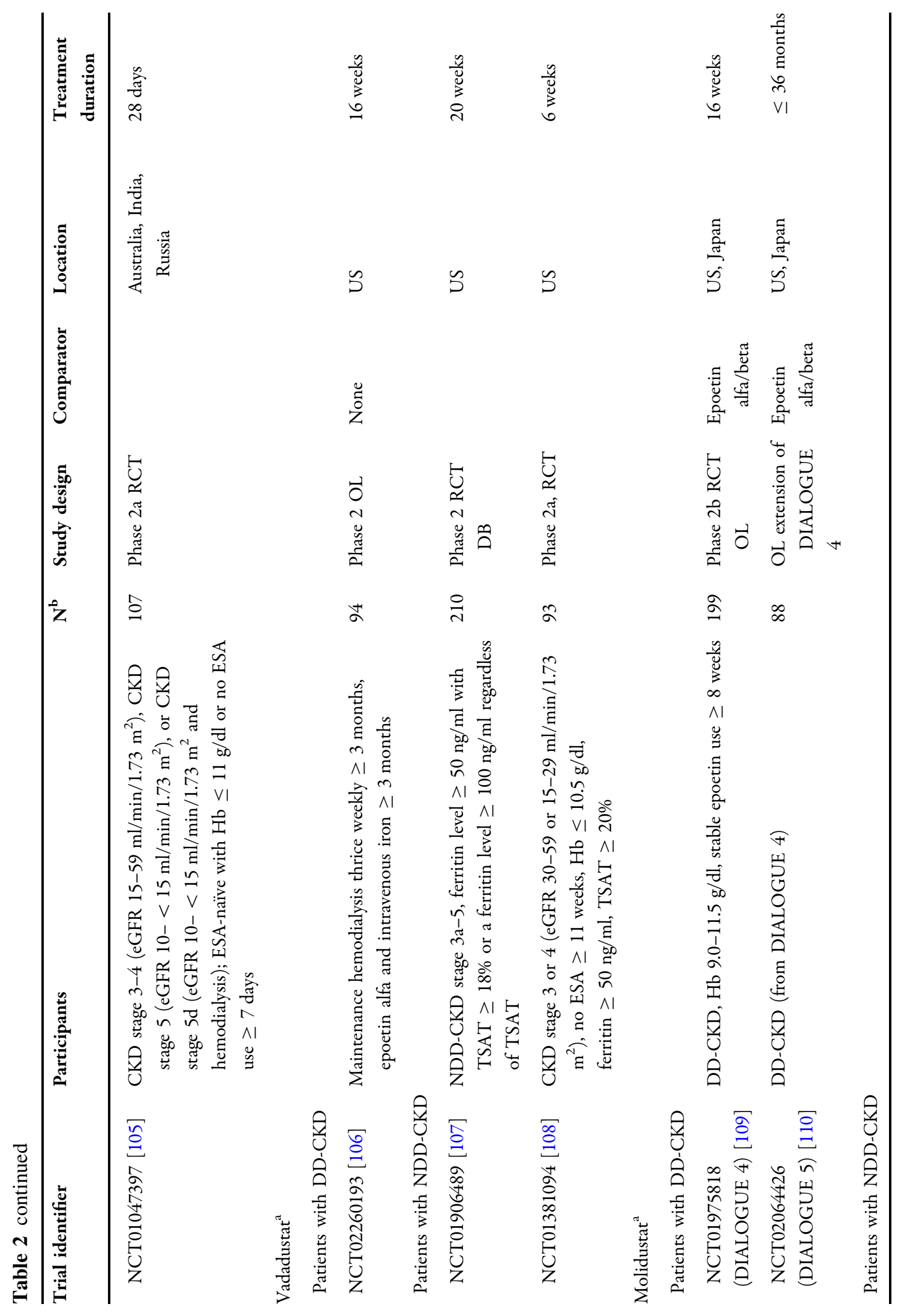









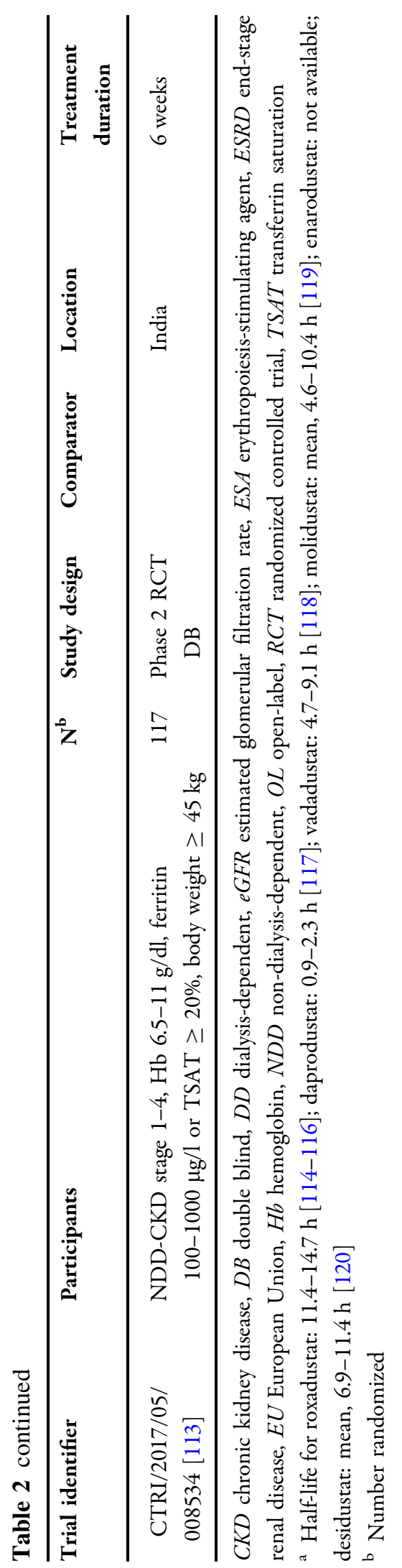

phase 3 randomized study [96] and in preliminary results from three international phase 3 studies $[92,97,98]$. In these studies, roxadustat was also associated with a reduced risk of rescue therapy (ESA or IV iron) and RBC transfusion [98] and reduced hepcidin levels compared with placebo (between group difference $-50 \mathrm{ng} / \mathrm{ml}$ ) [96]. Interim data from a phase 3 study showed that roxadustat was noninferior to darbepoetin alfa regarding $\mathrm{Hb}$ response in NDD-CKD patients [125]. Preliminary data from a Japanese phase 3 study showed that vadadustat was as effective as darbepoetin alfa in maintaining $\mathrm{Hb}$ levels in both ESA-naïve and ESA-converted NDD-CKD patients with anemia [126].

In both ESA-naïve and -experienced DD-CKD patients with anemia, roxadustat demonstrated non-inferiority or superiority in increasing $\mathrm{Hb}$ from baseline versus epoetin alfa or darbepoetin alfa in a Chinese phase 3 study [35] and in preliminary data from four international phase three studies [90-93]. Greater decreases in hepcidin from baseline were also observed with roxadustat versus epoetin alfa [35]. In a phase 3 Japanese study in ESA-naïve hemodialysis patients, daprodustat effectively corrected and maintained $\mathrm{Hb}$ levels within the target range (10-12 g/dl), decreased hepcidin levels, and increased TIBC [103]. Similarly, preliminary data demonstrated that vadadustat was as effective as darbepoetin alfa in maintaining $\mathrm{Hb}$ levels within the target range in Japanese patients on maintenance hemodialysis and resulted in reduced hepcidin levels and increased TIBC over 24 weeks, which was not observed in the darbepoetin alfa group [127].

HIF-PH inhibitors were well tolerated in phase 3 clinical studies, and adverse events (AEs) were consistent with those expected in a CKD population $[35,92,96,126,127]$. The most common AEs with roxadustat were hyperkalemia and metabolic acidosis in NDDCKD patients [96] and hyperkalemia in DDCKD patients [35]. Additionally, preliminary data from two further international phase 3 studies reported the most common AEs with roxadustat to be ESRD, urinary tract infection, pneumonia, and hypertension in NDD-CKD patients [128] and diarrhea in DD-CKD patients [129]. The most commonly reported AE with 


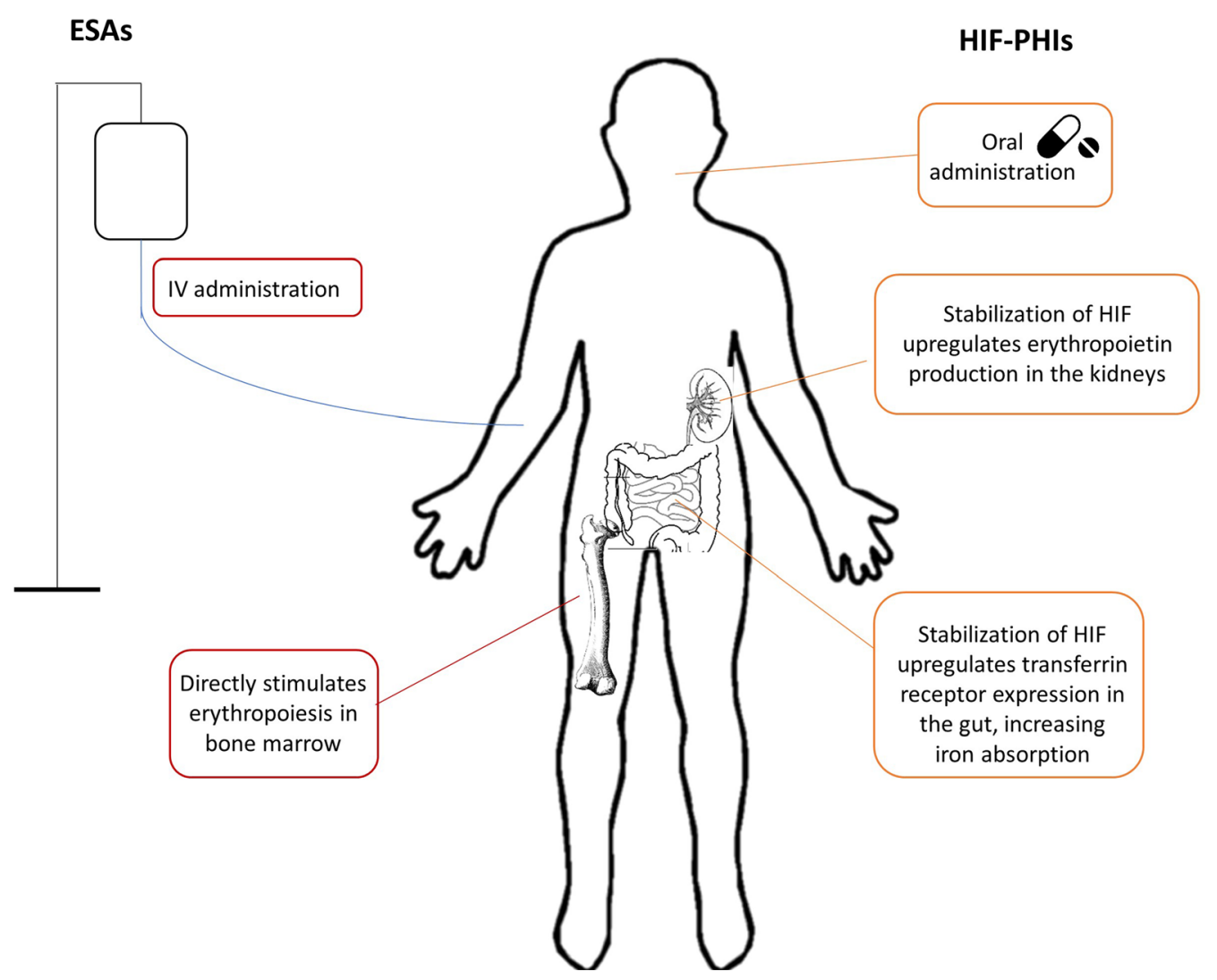

Fig. 2 Actions of erythropoiesis-stimulating agents (ESAs) and hypoxia-inducible factor prolyl hydroxylase inhibitors (HIFPHIs). $I V$ intravenous

daprodustat in DD-CKD patients was nasopharyngitis [103]. For vadadustat, these were nasopharyngitis, diarrhea, and constipation in NDD-CKD patients [126] and nasopharyngitis, constipation, and shunt stenosis in DD-CKD patients [127].

Preliminary results from a pooled safety analysis of NDD-CKD or stable DD-CKD patients with anemia indicated a similar or reduced risk of MACE and MACE plus heart failure or unstable angina requiring hospitalization (MACE+)with roxadustat versus placebo and epoetin alfa, respectively [130]. In incident DD-CKD patients with anemia, the HRs for MACE and MACE+ were $0.70 \quad(95 \%$ CI $0.51-0.97, P=0.03)$ and $0.66(95 \%$ CI $0.5-0.89$, $P=0.005)$, respectively, with roxadustat versus epoetin alfa [130]. Further analyses are needed to confirm these initial safety findings.

\section{HIF-PH Inhibitors in Development}

Several other HIF-PH inhibitors are in development, with data available for molidustat (BAY 85-3934), enarodustat (JTZ-951), and desidustat (Zyan1) (Table 2). These studies show dose-dependent $\mathrm{Hb}$ increases and maintenance of $\mathrm{Hb}$ (in NDD-CKD) and maintenance of $\mathrm{Hb}$ (in DDCKD) for molidustat [109], enarodustat [111, 112], and desidustat [113]. However, high $\mathrm{Hb}$ or a rapid rate of increase led to high incidences of early discontinuation from some studies of molidustat [109]. In the long-term extension studies DIALOGUE 3 and DIALOGUE $5, \mathrm{Hb}$ was maintained in the target range $(10-12 \mathrm{~g} / \mathrm{dl})$ for up to 36 months with molidustat, with a similar effect to darbepoetin or epoetin [110]. Increased TIBC and/or decreased hepcidin and/or ferritin was observed with these agents, which were generally well tolerated [109, 112, 113]. Furthermore, animal 
studies have indicated that prolonged exposure to roxadustat is not associated with pro-oncogenic activity [131, 132]. However, long-term clinical data are needed to confirm the safety of HIF-PH inhibitors regarding to cardiovascular events and carcinogenesis.

\section{Potential for Clinical Use of HIF-PH Inhibitors}

HIF-PH inhibitors may present several practical advantages for patients with anemia of CKD. In addition to their oral route of administration, HIF-PH inhibitors may provide closer to physiologic EPO levels than the intermittent high levels attained with ESA therapy [87, 95]. Beyond erythropoiesis stimulation, HIF-PH inhibitors may improve iron homeostasis [133] and therefore reduce patients' iron supplementation needs, thus potentially reducing costs and medication burden. Although data on the cost effectiveness of HIF-PH inhibitors are limited, a meta-analysis conducted to evaluate the cost effectiveness of roxadustat in Chinese patients with NDD-CKD confirmed that roxadustat was cost effective compared with placebo [134].

Evidence suggests that HIF-PH inhibitors may be efficacious without increasing inflammatory status [88], which could benefit patients with inflammation, associated with diabetic and non-diabetic kidney disease as well as those with acute inflammation (e.g., associated with infection). Although clinical data in patients who are ESA hyporesponsive are limited, key studies included patients with moderate inflammation, which is associated with reduced responsiveness to ESA therapy [135]. In the Chinese phase 3 study of roxadustat in patients with DD-CKD, similar increases in $\mathrm{Hb}$ levels were observed in patients with normal and elevated C-reactive protein levels $(\leq 4$ and $>4 \mathrm{mg} / \mathrm{l}$ ) [35]. In addition, preliminary phase 3 data showed greater mean changes in $\mathrm{Hb}$ in patients with elevated high-sensitivity C-reactive protein levels receiving roxadustat versus epoetin alfa (DD-CKD) [91] or placebo (NDD-CKD) [98]. In these patients with moderate inflammation, who are potentially hyporesponsive to ESA therapy, HIF-PH inhibitors may be an effective alternative that avoids the need for high-dose ESA therapy. Further studies are needed to confirm the efficacy of HIF-PH inhibitors in patients who are ESA hyporesponsive. Finally, HIF-PH inhibitors may confer a reduced risk of cardiovascular events compared with ESAs in incident dialysis patients as a preliminary phase 3 pooled analysis showed a lower risk of MACE and MACE + with roxadustat versus epoetin alfa [130]. Further studies are needed to confirm the practical benefits of HIF-PH inhibitors in patients with anemia of CKD.

Because HIF transcription factors regulate many biologic processes, there was concern that HIF-PH inhibitors may adversely affect cholesterol metabolism [136]. Based on animal studies, constitutive HIF-2 activation may theoretically suppress hepatic fatty acid $\beta$-oxidation and lipid synthesis and increase lipid storage capacity [136]. However, clinical studies showed reductions in total and low-density lipoprotein cholesterol (LDL-C) with roxadustat over 19-24 weeks [87, 94] and daprodustat over 24 weeks [103] as well as no changes in serum lipids with vadadustat over 16 or 20 weeks $[106,107]$ and only small changes in LDL-C with molidustat over 16 weeks [109]. Roxadustat phase 3 data showed decreases in low-density lipoprotein cholesterol versus placebo (NDD-CKD patients) [96] or versus ESA (DDCKD patients) [35]. One potential mechanism for this reduction in serum cholesterol with roxadustat is thought to be a HIF-dependent decrease in 3-hydroxy-3-methylglutaryl coenzyme A reductase levels, a rate-limiting enzyme in the cholesterol biosynthesis pathway [137].

\section{At-Home Anemia Management}

At-home care of CKD is one of the goals outlined in the recent Executive Order, Advancing American Kidney Health, which aims to improve the diagnosis and treatment of CKD [138]. Compared with conventional hemodialysis, at-home hemodialysis benefits include reductions in LV mass and hypertension and increased HR-QOL, although there are no 
observed differences in anemia management $[139,140]$.

Because they are orally administered, HIF-PH inhibitors may confer advantages for at-home CKD care. In ESRD patients receiving peritoneal dialysis, the more common modality for athome dialysis, roxadustat increased $\mathrm{Hb}$ to within the target range [141], and daprodustat pharmacokinetics were similar in patients receiving peritoneal dialysis or in-center hemodialysis, while $\mathrm{Hb}$ was maintained in those receiving peritoneal dialysis [142].

\section{CONCLUSIONS}

Anemia of CKD represents a considerable burden to both patients and the healthcare system. Although effective, the current standard of care is associated with inherent practical difficulties and safety concerns, including the increased risk of cardiovascular events and mortality. HIFPH inhibitors may offer advantages over ESAs through more physiologic and effective means of treating anemia of CKD.

\section{ACKNOWLEDGEMENTS}

Funding. This review, the Rapid Service, and Open Access Fees were funded by AstraZeneca.

Editorial Assistance. Sarah Greig, $\mathrm{PhD}$ (Auckland, NZ), and Meri D. Pozo, PhD, CMPP (New York, NY, USA), of inScience Communications, Springer Healthcare provided editorial support, which was funded by AstraZeneca.

Authorship. All named authors meet the International Committee of Medical Journal Editors (ICMJE) criteria for authorship for this article, take responsibility for the integrity of the work as a whole, and have given their approval for this version to be published.

Authorship Contributions. All authors wrote the first draft of the manuscript and participated in subsequent drafts, approved the submission of the manuscript, and are fully accountable for all aspects of the work.

Disclosures. Ramy M. Hanna and Elani Streja have nothing to disclose. Kamyar Kalantar-Zadeh reports personal fees from Abbott, AbbVie, Alexion, AMAG Pharma, Amgen, AstraZeneca, AVEO, Baxter, Chugai, Fresenius Medical Services, Genentech, Haymarket, Hospira, Fresenius Kabi USA, Keryx, Novartis, PCORI, Pfizer, Relypsa, Resverlogix, Sandoz, Sanofi, Shire, Vifor, UpToDate, and grants and personal fees from National Institutes of Health. None of the authors received honoraria for this work.

Compliance with Ethics Guidelines. This article is based on previously conducted studies and does not contain any studies with human participants or animals performed by any of the authors.

Open Access. This article is licensed under a Creative Commons Attribution-NonCommercial 4.0 International License, which permits any non-commercial use, sharing, adaptation, distribution and reproduction in any medium or format, as long as you give appropriate credit to the original author(s) and the source, provide a link to the Creative Commons licence, and indicate if changes were made. The images or other third party material in this article are included in the article's Creative Commons licence, unless indicated otherwise in a credit line to the material. If material is not included in the article's Creative Commons licence and your intended use is not permitted by statutory regulation or exceeds the permitted use, you will need to obtain permission directly from the copyright holder. To view a copy of this licence, visit http://creativecommons.org/licenses/by$\mathrm{nc} / 4.0 /$.

\section{REFERENCES}

1. St Peter WL, Guo H, Kabadi S, et al. Prevalence, treatment patterns, and healthcare resource utilization in Medicare and commercially insured nondialysis-dependent chronic kidney disease patients 
with and without anemia in the United States. BMC Nephrol. 2018;19:67.

2. Mikhail A, Brown C, Williams JA, et al. Renal association clinical practice guideline on Anaemia of Chronic Kidney Disease. BMC Nephrol. 2017;18: 345 .

3. Kidney Disease Improving Global Outcomes. KDIGO clinical practice guideline for anemia in chronic kidney disease. Kidney Int Suppl. 2012;2: 279-335.

4. Bonomini M, Del Vecchio L, Sirolli V, Locatelli F. New treatment approaches for the anemia of CKD. Am J Kidney Dis. 2016;67:133-42.

5. Babitt JL, Lin HY. Mechanisms of anemia in CKD. J Am Soc Nephrol. 2012;23:1631-4.

6. Hill NR, Fatoba ST, Oke JL, et al. Global prevalence of chronic kidney disease: a systematic review and meta-analysis. PLoS ONE. 2016;11:e0158765.

7. Stauffer ME, Fan T. Prevalence of anemia in chronic kidney disease in the United States. PLoS ONE. 2014;9:e84943.

8. Centers for Disease Control and Prevention. Chronic kidney disease in the United States, 2019. $2019 . \quad$ https://www.cdc.gov/kidneydisease/ publications-resources/2019-national-facts.html. Accessed 16 July 2020.

9. London GM. Left ventricular alterations and endstage renal disease. Nephrol Dial Transpl. 2002;17(Suppl 1):29-36.

10. Sarnak MJ, Levey AS, Schoolwerth AC, et al. Kidney disease as a risk factor for development of cardiovascular disease: a statement from the American Heart Association Councils on Kidney in Cardiovascular Disease, High Blood Pressure Research, Clinical Cardiology, and Epidemiology and Prevention. Circulation. 2003;108:2154-69.

11. Awan AA, Walther CP, Richardson PA, Shah $M$, Winkelmayer WC, Navaneethan SD. Prevalence, correlates and outcomes of absolute and functional iron deficiency anemia in nondialysis-dependent chronic kidney disease. Nephrol Dial Transpl. 2019. https://doi.org/10.1093/ndt/gfz192.

12. Toft $G$, Heide-Jorgensen $U$, van Haalen $H$, et al. Anemia and clinical outcomes in patients with nondialysis dependent or dialysis dependent severe chronic kidney disease: a Danish population-based study. J Nephrol. 2020;33:147-56.

13. Iimori S, Naito S, Noda Y, et al. Anaemia management and mortality risk in newly visiting patients with chronic kidney disease in Japan: The CKDROUTE study. Nephrology. 2015;20:601-8.

14. Abramson JL, Jurkovitz CT, Vaccarino V, Weintraub WS, McClellan W. Chronic kidney disease, anemia, and incident stroke in a middle-aged, communitybased population: the ARIC Study. Kidney Int. 2003;64:610-5.

15. Vlagopoulos PT, Tighiouart H, Weiner DE, et al. Anemia as a risk factor for cardiovascular disease and all-cause mortality in diabetes: the impact of chronic kidney disease. J Am Soc Nephrol. 2005;16: 3403-10.

16. Lee G, Choi S, Kim K, et al. Association of hemoglobin concentration and its change with cardiovascular and all-cause mortality. J Am Heart Assoc. 2018; 7:e007723.

17. Kim-Mitsuyama S, Soejima $\mathrm{H}$, Yasuda $\mathrm{O}$, et al. Anemia is an independent risk factor for cardiovascular and renal events in hypertensive outpatients with well-controlled blood pressure: a subgroup analysis of the ATTEMPT-CVD randomized trial. Hypertens Res. 2019;42:883-91.

18. Zoppini G, Targher G, Chonchol M, et al. Anaemia, independent of chronic kidney disease, predicts allcause and cardiovascular mortality in type 2 diabetic patients. Atherosclerosis. 2010;210:575-80.

19. Fishbane S, Spinowitz B. Update on anemia in ESRD and earlier stages of CKD: core curriculum 2018. Am J Kidney Dis. 2018;71:423-35.

20. Singh AK, Szczech L, Tang KL, et al. Correction of anemia with epoetin alfa in chronic kidney disease. N Engl J Med. 2006;355:2085-98.

21. Pfeffer MA, Burdmann EA, Chen CY, et al. A trial of darbepoetin alfa in type 2 diabetes and chronic kidney disease. N Engl J Med. 2009;361:2019-32.

22. Mukhopadhyay P, Sinha U, Banerjee J, Choudhury AR, Philips CA. The effects in correction of anaemia in chronic kidney disease with erythropoietin therapy-preference to cardiovascular, neurologic and general well-being of patients from a tertiary care centre. J Indian Med Assoc. 2012;110:885-8.

23. Covic A, Jackson J, Hadfield A, Pike J, Siriopol D. Real-world impact of cardiovascular disease and anemia on quality of life and productivity in patients with non-dialysis-dependent chronic kidney disease. Adv Ther. 2017;34:1662-72.

24. Finkelstein FO, Wuerth D, Finkelstein SH. Health related quality of life and the CKD patient: challenges for the nephrology community. Kidney Int. 2009; 76:946-52. 
25. Rao M, Pereira BJ. Optimal anemia management reduces cardiovascular morbidity, mortality, and costs in chronic kidney disease. Kidney Int. 2005;68:1432-8.

26. Garlo K, Williams D, Lucas L, et al. Severity of anemia predicts hospital length of stay but not readmission in patients with chronic kidney disease: a retrospective cohort study. Medicine (Baltimore). 2015;94:e964.

27. Maddux FW, Shetty S, del Aguila MA, Nelson MA, Murray BM. Effect of erythropoiesis-stimulating agents on healthcare utilization, costs, and outcomes in chronic kidney disease. Ann Pharmacother. 2007;41:1761-9.

28. Nissenson AR, Wade S, Goodnough T, Knight K, Dubois RW. Economic burden of anemia in an insured population. J Manag Care Pharm. 2005;11: $565-74$.

29. Arantes LH Jr, Crawford J, Gascon P, et al. A quick scoping review of efficacy, safety, economic, and health-related quality-of-life outcomes of short- and long-acting erythropoiesis-stimulating agents in the treatment of chemotherapy-induced anemia and chronic kidney disease anemia. Crit Rev Oncol Hematol. 2018;129:79-90.

30. Locatelli F, Pisoni RL, Combe C, et al. Anaemia in haemodialysis patients of five European countries: association with morbidity and mortality in the Dialysis Outcomes and Practice Patterns Study (DOPPS). Nephrol Dial Transpl. 2004;19:121-32.

31. Bennett WM. A multicenter clinical trial of epoetin beta for anemia of end-stage renal disease. J Am Soc Nephrol. 1991;1:990-8.

32. Rosati A, Ravaglia F, Panichi V. Improving erythropoiesis stimulating agent hyporesponsiveness in hemodialysis patients: the role of hepcidin and hemodiafiltration online. Blood Purif. 2018;45: $139-46$.

33. Sinha SD, Bandi VK, Bheemareddy BR, et al. Efficacy, tolerability and safety of darbepoetin alfa injection for the treatment of anemia associated with chronic kidney disease (CKD) undergoing dialysis: a randomized, phase-III trial. BMC Nephrol. 2019;20:90.

34. Woodland AL, Murphy SW, Curtis BM, Barrett BJ. Costs associated with intravenous darbepoetin versus epoetin therapy in hemodialysis patients: a randomized controlled trial. Can J Kidney Health Dis. 2017;4:2054358117716461.

35. Chen N, Hao C, Liu BC, et al. Roxadustat treatment for anemia in patients undergoing long-term dialysis. N Engl J Med. 2019;381:1011-22.
36. Gupta N, Wish JB. Hypoxia-inducible factor prolyl hydroxylase inhibitors: a potential new treatment for anemia in patients with CKD. Am J Kidney Dis. 2017;69:815-26.

37. Kaplan JM, Sharma N, Dikdan S. Hypoxia-inducible factor and its role in the management of anemia in chronic kidney disease. Int J Mol Sci. 2018;19:E389.

38. Sakaguchi Y, Hamano T, Wada A, Masakane I. Types of erythropoietin-stimulating agents and mortality among patients undergoing hemodialysis. J Am Soc Nephrol. 2019;30:1037-48.

39. Macdougall IC, Hutton RD, Cavill I, Coles GA, Williams JD. Poor response to treatment of renal anaemia with erythropoietin corrected by iron given intravenously. BMJ. 1989;299:157-8.

40. Agarwal R. Nonhematological benefits of iron. Am J Nephrol. 2007;27:565-71.

41. Hayat A. Safety issues with intravenous iron products in the management of anemia in chronic kidney disease. Clin Med Res. 2008;6:93-102.

42. Macdougall IC, Bircher AJ, Eckardt KU, et al. Iron management in chronic kidney disease: conclusions from a "Kidney Disease: Improving Global Outcomes" (KDIGO) Controversies Conference. Kidney Int. 2016;89:28-39.

43. Vaziri ND. Safety issues in iron treatment in CKD. Semin Nephrol. 2016;36:112-8.

44. Macdougall IC, Vernon K. Complement activationrelated pseudo-allergy: a fresh look at hypersensitivity reactions to intravenous iron. Am J Nephrol. 2017;45:60-2.

45. Wang C, Graham DJ, Kane RC, et al. Comparative risk of anaphylactic reactions associated with intravenous iron products. JAMA. 2015;314:2062-8.

46. Roger SD. Practical considerations for iron therapy in the management of anaemia in patients with chronic kidney disease. Clin Kidney J. 2017;10: i9-i15.

47. Kaushik T, Yaqoob MM. Lessons learned from peginesatide in the treatment of anemia associated with chronic kidney disease in patients on dialysis. Biologics. 2013;7:243-6.

48. U.S. Food and Drug Administration. FDA drug safety communication: modified dosing recommendations to improve the safe use of erythropoiesis-stimulating agents (ESAs) in chronic kidney disease. 2011. https://www.fda.gov/drugs/drugsafety-and-availability/fda-drug-safetycommunication-modified-dosing- 
recommendations-improve-safe-use-erythropoiesis. Accessed 23 July 2020.

49. Goodkin DA, Fuller DS, Robinson BM, et al. Naturally occurring higher hemoglobin concentration does not increase mortality among hemodialysis patients. J Am Soc Nephrol. 2011;22:358-65.

50. Akaishi M, Hiroe M, Hada Y, et al. Effect of anemia correction on left ventricular hypertrophy in patients with modestly high hemoglobin level and chronic kidney disease. J Cardiol. 2013;62:249-56.

51. Hayashi T, Uemura Y, Kumagai M, et al. Effect of achieved hemoglobin level on renal outcome in non-dialysis chronic kidney disease (CKD) patients receiving epoetin beta pegol: MIRcerA Clinical Evidence on Renal Survival in CKD patients with renal anemia (MIRACLE-CKD Study). Clin Exp Nephrol. 2019;23:349-61.

52. Ritz E, Laville M, Bilous RW, et al. Target level for hemoglobin correction in patients with diabetes and CKD: primary results of the Anemia Correction in Diabetes (ACORD) Study. Am J Kidney Dis. 2007;49:194-207.

53. Drueke TB, Locatelli F, Clyne N, et al. Normalization of hemoglobin level in patients with chronic kidney disease and anemia. N Engl J Med. 2006;355: 2071-84.

54. Solomon SD, Uno H, Lewis EF, et al. Erythropoietic response and outcomes in kidney disease and type 2 diabetes. N Engl J Med. 2010;363:1146-55.

55. Park H, Liu X, Henry L, Harman J, Ross EA. Trends in anemia care in non-dialysis-dependent chronic kidney disease (CKD) patients in the United States (2006-2015). BMC Nephrol. 2018;19:318.

56. Li S, Guo H, Kabadi S, et al. Unexpected medical consequences of revised ESA label in non-dialysisdependent chronic kidney disease patients with anemia. J Am Soc Nephrol. 2016;27:814A.

57. Collister D, Komenda P, Hiebert B, et al. The effect of erythropoietin-stimulating agents on health-related quality of life in anemia of chronic kidney disease: a systematic review and meta-analysis. Ann Intern Med. 2016;164:472-8.

58. Spinowitz B, Pecoits-Filho R, Winkelmayer WC, et al. Economic and quality of life burden of anemia on patients with CKD on dialysis: a systematic review. J Med Econ. 2019;22:593-604.

59. Johansen KL, Finkelstein FO, Revicki DA, et al. Systematic review of the impact of erythropoiesisstimulating agents on fatigue in dialysis patients. Nephrol Dial Transpl. 2012;27:2418-25.
60. Muirhead N, Keown PA, Churchill DN, et al. Dialysis patients treated with Epoetin alpha show improved exercise tolerance and physical function: a new analysis of the Canadian Erythropoietin Study Group trial. Hemodial Int. 2011;15:87-94.

61. Fox KM, Yee J, Cong Z, et al. Transfusion burden in non-dialysis chronic kidney disease patients with persistent anemia treated in routine clinical practice: a retrospective observational study. BMC Nephrol. 2012;13:5.

62. Bohlius J, Bohlke K, Castelli R, et al. Management of cancer-associated anemia with erythropoiesis-stimulating agents: ASCO/ASH clinical practice guideline update. Blood Adv. 2019;3:1197-210.

63. Lattanzio F, Corsonello A, Montesanto A, et al. Disentangling the impact of chronic kidney disease, anemia, and mobility limitation on mortality in older patients discharged from hospital. J Gerontol A Biol Sci Med Sci. 2015;70:1120-7.

64. Kuragano T, Mizusaki K, Kimura T, Nakanishi T. Anemia management considering the pathophysiology of elderly chronic kidney disease patients. Contrib Nephrol. 2019;198:135-43.

65. Dousdampanis P, Trigka K, Fourtounas C. Prevalence of anemia in patients with type II diabetes and mild to moderate chronic kidney disease and the impact of anti-RAS medications. Saudi J Kidney Dis Transpl. 2014;25:552-7.

66. Pappa M, Dounousi E, Duni A, Katopodis K. Less known pathophysiological mechanisms of anemia in patients with diabetic nephropathy. Int Urol Nephrol. 2015;47:1365-72.

67. Fujita Y, Doi Y, Hamano T, et al. Low erythropoietin levels predict faster renal function decline in diabetic patients with anemia: a prospective cohort study. Sci Rep. 2019;9:14871.

68. Stevens PE. Anaemia, diabetes and chronic kidney disease: where are we now? J Ren Care. 2012;38(Suppl 1):67-77.

69. Mehdi U, Toto RD. Anemia, diabetes, and chronic kidney disease. Diabetes Care. 2009;32:1320-6.

70. Winocour PH. Diabetes and chronic kidney disease: an increasingly common multi-morbid disease in need of a paradigm shift in care. Diabet Med. 2018;35:300-5.

71. Fowler MJ. Microvascular and macrovascular complications of diabetes. Clinical Diabetes. 2008;26: 77-82.

72. Bajaj S, Makkar BM, Abichandani VK, et al. Management of anemia in patients with diabetic kidney 
disease: a consensus statement. Indian J Endocrinol Metab. 2016;20:268-81.

73. Portoles J, Gorriz JL, Rubio E, et al. The development of anemia is associated to poor prognosis in NKF/KDOQI stage 3 chronic kidney disease. BMC Nephrol. 2013;14:2.

74. Moss AH, Davison SN. How the ESRD quality incentive program could potentially improve quality of life for patients on dialysis. Clin J Am Soc Nephrol. 2015;10:888-93.

75. Valliant A, Hofmann RM. Managing dialysis patients who develop anemia caused by chronic kidney disease: focus on peginesatide. Int J Nanomedicine. 2013;8:3297-307.

76. Rostoker G, Griuncelli M, Loridon C, et al. Hemodialysis-associated hemosiderosis in the era of erythropoiesis-stimulating agents: a MRI study. Am J Med. 2012;125(991-9):e1.

77. Besarab A, Bolton WK, Browne JK, et al. The effects of normal as compared with low hematocrit values in patients with cardiac disease who are receiving hemodialysis and epoetin. N Engl J Med. 1998;339: 584-90.

78. Gafter-Gvili A, Ayalon-Dangur I, Cooper L, et al. Posttransplantation anemia in kidney transplant recipients: a retrospective cohort study. Medicine (Baltimore). 2017;96:e7735.

79. Gurlek Demirci B, Sezer S, Sayin CB, et al. Posttransplantation anemia predicts cardiovascular morbidity and poor graft function in kidney transplant recipients. Transpl Proc. 2015;47:1178-81.

80. Tsujita M, Kosugi T, Goto N, et al. The effect of maintaining high hemoglobin levels on long-term kidney function in kidney transplant recipients: a randomized controlled trial. Nephrol Dial Transpl. 2019;34:1409-16.

81. Kitamura K, Nakai K, Fujii H, Ishimura T, Fujisawa M, Nishi S. Pre-transplant erythropoiesis-stimulating agent hypo-responsiveness and post-transplant anemia. Transpl Proc. 2015;47:1820-4.

82. Haase VH. HIF-prolyl hydroxylases as therapeutic targets in erythropoiesis and iron metabolism. Hemodial Int. 2017;21(Suppl 1):S110-S12424.

83. Del Balzo U, Signore PE, Walkinshaw G, et al. Nonclinical characterization of the HIF-prolyl hydroxylase inhibitor roxadustat, a novel treatment for anemia of chronic kidney disease. J Pharmacol Exp Ther. 2020. https://doi.org/10.1124/jpet.120. 265181.
84. Kato S, Ochiai N, Takano H, et al. TP0463518, a novel prolyl hydroxylase inhibitor, specifically induces erythropoietin production in the liver. J Pharmacol Exp Ther. 2019;371:675-83.

85. Shah YM, Matsubara T, Ito S, Yim SH, Gonzalez FJ. Intestinal hypoxia-inducible transcription factors are essential for iron absorption following iron deficiency. Cell Metab. 2009;9:152-64.

86. Chen N, Qian J, Chen J, et al. Phase 2 studies of oral hypoxia-inducible factor prolyl hydroxylase inhibitor FG-4592 for treatment of anemia in China. Nephrol Dial Transpl. 2017;32:1373-86.

87. Provenzano R, Besarab A, Wright S, et al. Roxadustat (FG-4592) versus epoetin alfa for anemia in patients receiving maintenance hemodialysis: a phase 2, randomized, 6- to 19-week, open-label, activecomparator, dose-ranging, safety and exploratory efficacy study. Am J Kidney Dis. 2016;67:912-24.

88. Besarab A, Chernyavskaya E, Motylev I, et al. Roxadustat (FG-4592): correction of anemia in incident dialysis patients. J Am Soc Nephrol. 2016;27:1225-333.

89. Akizawa T, Ueno M, Shiga T, Reusch M. Oral roxadustat three times weekly in ESA-naive and ESAconverted patients with anemia of chronic kidney disease on hemodialysis: results from two phase 3 studies. Ther Apher Dial. 2019. https://doi.org/10. 1111/1744-9987.13468.

90. Charytan C, Manllo-Karim R, Martin ER, et al. SIERRAS: a phase 3, open-label, randomized, activecontrolled study of the efficacy and safety of roxadustat in the maintenance treatment of anemia in subjects with ESRD on stable dialysis [abstract SAPO227]. J Am Soc Nephrol. 2019;30:822.

91. Fishbane S, Pollock CA, El-Shahawy MA, et al. ROCKIES: an international, phase 3, randomized, open-label, active-controlled study of roxadustat for anemia in dialysis-dependent CKD patients [abstract TH-OR022]. J Am Soc Nephrol. 2019;30:6.

92. Esposito C, Csiky B, Tataradze A, Reusch M, Han C, Sulowicz W. Two phase 3, multicenter, randomized studies of intermittent oral roxadustat in anemic CKD patients on (PYRENEES) and not on (ALPS) dialysis [abstract SA-PO225]. J Am Soc Nephrol. 2019;30:822.

93. Provenzano R, Evgeny S, Liubov E, et al. HIMALAYAS: a phase 3, randomized, open-label, activecontrolled study of the efficacy and safety of roxadustat in the treatment of anemia in incidentdialysis patients [abstract TH-OR021]. J Am Soc Nephrol. 2019;30:5. 
94. Provenzano R, Besarab A, Sun $\mathrm{CH}$, et al. Oral hypoxia-inducible factor prolyl hydroxylase inhibitor roxadustat (FG-4592) for the treatment of anemia in patients with CKD. Clin J Am Soc Nephrol. 2016;11:982-91.

95. Besarab A, Provenzano R, Hertel J, et al. Randomized placebo-controlled dose-ranging and pharmacodynamics study of roxadustat (FG-4592) to treat anemia in nondialysis-dependent chronic kidney disease (NDD-CKD) patients. Nephrol Dial Transpl. 2015;30:1665-733.

96. Chen N, Hao C, Peng X, et al. Roxadustat for anemia in patients with kidney disease not receiving dialysis. N Engl J Med. 2019;381:1001-100.

97. Coyne DW, Roger SD, Shin SK, et al. ANDES: a phase 3, randomized, double-blind, placebo controlled study of the efficacy and safety of roxadustat for the treatment of anemia in CKD patients not on dialysis [abstract SA-PO228]. J Am Soc Nephrol. 2019;30:822-3.

98. Fishbane S, El-Shahawy MA, Pecoits-Filho R, et al. OLYMPUS: a phase 3, randomized, double-blind, placebo-controlled, international study of roxadustat efficacy in patients with non-dialysis-dependent (NDD) CKD and anemia [abstract TH-OR023]. J Am Soc Nephrol. 2019;30:6.

99. Akizawa T, Tsubakihara Y, Nangaku M, et al. Effects of daprodustat, a novel hypoxia-inducible factor prolyl hydroxylase inhibitor on anemia management in japanese hemodialysis subjects. Am J Nephrol. 2017;45:127-35.

100. Holdstock L, Meadowcroft AM, Maier R, et al. Fourweek studies of oral hypoxia-inducible factor-prolyl hydroxylase inhibitor GSK1278863 for treatment of anemia. J Am Soc Nephrol. 2016;27:1234-44.

101. Cizman B, Sykes AP, Paul G, Zeig S, Cobitz AR. An exploratory study of daprodustat in erythropoietinhyporesponsive subjects. Kidney Int Rep. 2018;3: 841-50.

102. Meadowcroft AM, Cizman B, Holdstock L, et al. Daprodustat for anemia: a 24-week, open-label, randomized controlled trial in participants on hemodialysis. Clin Kidney J. 2019;12:139-48.

103. Tsubakihara Y, Akizawa T, Nangaku M, et al. A 24-week anemia correction study of daprodustat in japanese dialysis patients. Ther Apher Dial. 2020;24: 108-14.

104. Holdstock L, Cizman B, Meadowcroft AM, et al. Daprodustat for anemia: a 24-week, open-label, randomized controlled trial in participants with chronic kidney disease. Clin Kidney J. 2019;12: 129-38.
105. Brigandi RA, Johnson B, Oei C, et al. A novel hypoxia-inducible factor-prolyl hydroxylase inhibitor (GSK1278863) for anemia in CKD: a 28-day, phase $2 \mathrm{~A}$ randomized trial. Am J Kidney Dis. 2016;67:861-71.

106. Haase VH, Chertow GM, Block GA, et al. Effects of vadadustat on hemoglobin concentrations in patients receiving hemodialysis previously treated with erythropoiesis-stimulating agents. Nephrol Dial Transpl. 2019;34:90-9.

107. Pergola PE, Spinowitz BS, Hartman CS, Maroni BJ, Haase VH. Vadadustat, a novel oral HIF stabilizer, provides effective anemia treatment in nondialysisdependent chronic kidney disease. Kidney Int. 2016;90:1115-22.

108. Martin ER, Smith MT, Maroni BJ, Zuraw QC, deGoma EM. Clinical trial of vadadustat in patients with anemia secondary to stage 3 or 4 chronic kidney disease. Am J Nephrol. 2017;45:380-8.

109. Macdougall IC, Akizawa T, Berns JS, Bernhardt T, Krueger T. Effects of Molidustat in the Treatment of Anemia in CKD. Clin J Am Soc Nephrol. 2019;14: 28-39.

110. Akizawa T, Macdougall IC, Berns JS, et al. Long-term efficacy and safety of molidustat for anemia in chronic kidney disease: DIALOGUE extension studies. Am J Nephrol. 2019;49:271-80.

111. Akizawa T, Nangaku M, Yamaguchi T, et al. Enarodustat, conversion and maintenance therapy for anemia in hemodialysis patients: a randomized, placebo-controlled phase $2 \mathrm{~b}$ trial followed by longterm trial. Nephron. 2019;143:77-85.

112. Akizawa T, Nangaku M, Yamaguchi T, et al. A placebo-controlled, randomized trial of enarodustat in patients with chronic kidney disease followed by long-term trial. Am J Nephrol. 2019;49:165-74.

113. Parmar DV, Kansagra KA, Patel JC, et al. Outcomes of desidustat treatment in people with anemia and chronic kidney disease: a phase 2 study. Am J Nephrol. 2019;49:470-8.

114. Shibata T, Nomura Y, Takada A, Aoki S, Katashima M, Murakami H. Evaluation of the effect of lanthanum carbonate hydrate on the pharmacokinetics of roxadustat in non-elderly healthy adult male subjects. J Clin Pharm Ther. 2018;43:633-9.

115. Shibata T, Nomura Y, Takada A, et al. Evaluation of food and spherical carbon adsorbent effects on the pharmacokinetics of roxadustat in healthy nonelderly adult male Japanese subjects. Clin Pharmacol Drug Dev. 2019;8:304-13. 
116. Groenendaal-van de Meent D, Adel MD, et al. Effect of moderate hepatic impairment on the pharmacokinetics and pharmacodynamics of roxadustat, an oral hypoxia-inducible factor prolyl hydroxylase inhibitor. Clin Drug Investig. 2016;36:743-51.

117. Hara K, Takahashi N, Wakamatsu A, Caltabiano S. Pharmacokinetics, pharmacodynamics and safety of single, oral doses of GSK1278863, a novel HIF-prolyl hydroxylase inhibitor, in healthy Japanese and Caucasian subjects. Drug Metab Pharmacokinet. 2015;30:410-8.

118. Buch A, Maroni BJ, Hartman CS. Dose exposure relationship of AKB-6548 is independent of the level of renal function. J Am Soc Nephrol. 2015;26: 747A.

119. Bottcher M, Lentini S, Arens ER, et al. First-in-manproof of concept study with molidustat: a novel selective oral HIF-prolyl hydroxylase inhibitor for the treatment of renal anaemia. Br J Clin Pharmacol. 2018;84:1557-655.

120. Kansagra KA, Parmar D, Jani RH, et al. Phase I clinical study of ZYAN1, a novel prolyl-hydroxylase (PHD) inhibitor to evaluate the safety, tolerability, and pharmacokinetics following oral administration in healthy volunteers. Clin Pharmacokinet. 2018;57:87-102.

121. Astellas. Evrenzo ${ }^{\circledR}$ (roxadustat) tablets approved in Japan for the treatment of anemia associated with chronic kidney disease in dialysis patients. 2019. https://www.astellas.com/en/news/15096. Accessed 23 July 2020.

122. AstraZeneca. Roxadustat approved in China for the treatment of anaemia in non-dialysis-dependent patients with chronic kidney disease. 2019. https:// www.astrazeneca.com/media-centre/press-releases/ 2019/roxadustat-approved-in-china-for-the-treatment-of-anaemia-in-non-dialysis-dependent-patientswith-chronic-kidney-disease-22082019.html. Accessed 23 July 2020.

123. Akebia Therapeutics. Akebia Therapeutics announces approval of vadadustat in Japan for the treatment of anemia due to chronic kidney disease in dialysis-dependent and non-dialysis dependent adult patients. 2020. https://ir.akebia.com/pressreleases. Accessed 23 July 2020.

124. GlaxoSmithKline. GSK receives first regulatory approval for Duvroq (daprodustat) in Japan for patients with anaemia due to chronic kidney disease. 2020. https://www.gsk.com/en-gb/media/ press-releases. Accessed 23 July 2020.

125. Barratt J, Andrić B, Tataradze A, et al. Roxadustat for the treatment of anaemia in chronic kidney disease patients not on dialysis: a phase 3 , randomised, open-label, active-controlled study [abstract MO001]. Nephrol Dial Transpl. 2020;35:101-2.

126. Nangaku M, Kondo K, Kokado Y, et al. Randomized, open-label, active-controlled (darbepoetin alfa), phase 3 study of vadadustat for treating anemia in non-dialysis-dependent CKD patients in Japan [abstract SA-PO229]. J Am Soc Nephrol. 2019;30:823.

127. Nangaku M, Kondo K, Ueta K, et al. Randomized, double-blinded, active-controlled (darbepoetin alfa), phase 3 study of vadadustat in CKD patients with anemia on hemodialysis in Japan [abstract THOR024]. J Am Soc Nephrol. 2019;30:6.

128. ClinicalTrials.gov. Safety and efficacy study of roxadustat to treat anemia in patients with chronic kidney disease (CKD), not on dialysis. 2019. https:// clinicaltrials.gov/ct2/show/NCT02174627. Accessed 23 July 2020.

129. ClinicalTrials.gov. Safety and efficacy study of roxadustat to treat anemia in patients with chronic kidney disease, on dialysis. 2019. https:// clinicaltrials.gov/ct2/show/NCT02174731. Accessed 23 July 2020.

130. Provenzano R, Fishbane S, Wei L-J, et al. Pooled efficacy and cardiovascular (CV) analyses of roxadustat in the treatment of anemia in CKD patients on and not on dialysis [abstract FR-OR131]. J Am Soc Nephrol. 2019;30:B1.

131. Beck J, Henschel C, Chou J, Lin A, Del Balzo U. Evaluation of the carcinogenic potential of Roxadustat (FG-4592), a small molecule inhibitor of hypoxia-inducible factor prolyl hydroxylase in CD1 mice and Sprague Dawley rats. Int $\mathrm{J}$ Toxicol. 2017;36:427-39.

132. Seeley TW, Sternlicht MD, Klaus SJ, Neff TB, Liu DY. Induction of erythropoiesis by hypoxia-inducible factor prolyl hydroxylase inhibitors without promotion of tumor initiation, progression, or metastasis in a VEGF-sensitive model of spontaneous breast cancer. Hypoxia. 2017;5:1-9.

133. Dhillon S. Roxadustat: first global approval. Drugs. 2019;79:563-72.

134. Hu Z, Tao H, Shi A, Pan J. The efficacy and economic evaluation of roxadustat treatment for anemia in patients with kidney disease not receiving dialysis. Expert Rev Pharmacoecon Outcomes Res. 2020;20:411-8.

135. Johnson DW, Pollock CA, Macdougall IC. Erythropoiesis-stimulating agent hyporesponsiveness. Nephrology. 2007;12:321-30. 
136. Rankin EB, Rha J, Selak MA, et al. Hypoxia-inducible factor 2 regulates hepatic lipid metabolism. Mol Cell Biol. 2009;29:4527-38.

137. Chow A, Gervasi D, Guo G, Signore P, del Balzo U, Walkinshaw G. Roxadustat enhances degradation of 3-hydroxy-3-methylglutaryl coenzyme A reductase (HMGCR) in a HIF and INSIG dependent manner. Keystone Symposia; January 19-23 2020; Keystone, CO.

138. The White House. Executive Order on Advancing American Kidney Health. 2019. https://www. whitehouse.gov/presidential-actions/executive-orderadvancing-american-kidney-health/. Accessed 23 July 2020 .

139. Culleton BF, Walsh M, Klarenbach SW, et al. Effect of frequent nocturnal hemodialysis vs conventional hemodialysis on left ventricular mass and quality of life: a randomized controlled trial. JAMA. 2007;298: 1291-9.

140. Chan CT, Floras JS, Miller JA, Richardson RM, Pierratos A. Regression of left ventricular hypertrophy after conversion to nocturnal hemodialysis. Kidney Int. 2002;61:2235-9.

141. Akizawa T, Otsuka T, Reusch M, Ueno M. Intermittent oral dosing of roxadustat in peritoneal dialysis chronic kidney disease patients with anemia: a randomized, phase 3 , multicenter. Open-Label Study Ther Apher Dial. 2020;24:115-25.

142. Caltabiano S, Cizman B, Burns O, et al. Effect of renal function and dialysis modality on daprodustat and predominant metabolite exposure. Clin Kidney J. 2019;12:693-701. 